\title{
Serum Liver Enzyme Levels: A Hospital-Based Observational Study from Kashmir
}

\author{
Gowhar Rashid ${ }^{1}$, Gulzar Ahmad Bhat ${ }^{1}$, Tahseen Bilal Rather ${ }^{1}$, Ahsan Rashid ${ }^{2}$, Jaffar Wani $^{3}$ \& Syed Mudassar ${ }^{4 *}$ \\ ${ }^{1}$ Department of Clinical Biochemistry, SKIMS, Kashmir, India. ${ }^{2}$ RIMT University, Punjab, India. ${ }^{3}$ University of Kashmir, India. \\ ${ }^{4} *$ Professor and Head, Clinical Biochemistry, SKIMS, Kashmir, India. Email: syed.mudassar@skims.ac in

DOI: http://doi.org/10.38177/AJBSR.2021.3204

Copyright: (92021 Gowhar Rashid et al. This is an open access article distributed under the terms of the Creative Commons Attribution License, which permits unrestricted use, distribution, and reproduction in any medium, provided the original author and source are credited.

\section{ABSTRACT}

Background: Liver disorders are one of the most common causes of health problems all over the world owing to evolving lifestyles and dietary patterns. In this retrospective study, we aimed to explore the impact of dietary habits on liver enzymes among the Kashmiri population.

Methods: A total of 18462 patients were registered in the outpatient/Inpatient sections of the tertiary care hospital of Kashmir for various investigations from March to November 2020. In the liver function profile, a total of 7715 samples were tested for Aspartate transaminase (AST), 12084 for Alanine transaminase (ALT), 12573 for total bilirubin, 131472 for albumin, Alkaline phosphatase for 12762, and 12181 for Lactate dehydrogenase $(\mathrm{LDH})$ parameters.

Results: The average value documented for aspartate transaminase (AST), alanine transaminase $(A L T)$, total bilirubin, total protein, and albumin were $39.06 \mathrm{U} / \mathrm{L}, 38.81 \mathrm{U} / \mathrm{L}, 0.91 \mathrm{mg} / \mathrm{dL}, 7.31 \mathrm{~g} / \mathrm{dL}$, and $4.22 \mathrm{~g} / \mathrm{dL}$ respectively which are considered normal. However, ALP and $L D H$ were found to be little elevated among various liver function parameters. Alkaline phosphatase (ALP) and Lactate dehydrogenase (LDH) had average values of 148.66 and $260.25 U / L$, respectively.

Conclusion: Our findings revealed the rising levels of alkaline phosphatase (ALP) and Lactate dehydrogenase (LDH), this paradigm shift could be attributed to a sedentary lifestyle and unique dietary habits.

Keywords: LFT, Kashmir, Biochemical investigations, Liver disease.

\section{Introduction}

Liver disease rates are steadily increasing over the years and about 2 million people die each year from liver disease, 1 million from cirrhosis, and 1 million from viral hepatitis and hepatocellular carcinoma $(\mathrm{HCC})^{1}$ and representing them the $11^{\text {th }}$ and $16^{\text {th }}$ most common causes of death, respectively.

They are responsible for 3.5 percent of all deaths on the globe. The burden is likely to be higher when acute hepatitis and alcohol-use disorders (AUDs) are considered. In the United States, liver diseases are the second leading cause of death among all digestive diseases ${ }^{2}$. Non-alcoholic fatty liver disease (NAFLD) is a major health problem in Western countries, affecting 30\% of the adult population and $60 \%-80 \%$ of patients with diabetes mellitus and/or obesity ${ }^{3}$. According to the 2011 survey of National Health and Nutrition, the incidence of NAFLD, obesity, and diabetes mellitus have all risen in unison since the 1988-1994 study revealing that NAFLD is a connecting link with obesity and diabetes ${ }^{4}$.

India's liver disease-related deaths have reached 259,749 per year. It accounts for 2.95 percent of all deaths. India ranks $63^{\text {rd }}$ in the world with a death rate of 22.93 per 100,000 of population ${ }^{5}$. With the global epidemic of obesity, hypertension, and type II diabetes, there is a rise in the incidence and prevalence of NAFLD in India ${ }^{6,7}$.

Kashmir is known for its unique dietary habit of having a rich fat diet and a special Kashmiri cuisine called wazwan, comprising of 7 to 36 dishes of meat or beef and chicken. Ethnic meat products are high in calories, saturated fatty acids, and cholesterol. High animal fat diets are associated with several types of disorders such as obesity, hypertension, cardiovascular diseases, and coronary heart diseases ${ }^{7,8}$. According to some of the studies, 
Kashmir is at the brim of liver disease mainly NAFLD due to the diet which is heavily loaded with fat ${ }^{9}$.In Kashmir, the overall prevalence of NAFLD was $7.2 \%$ with the highest prevalence in the age group of $16-18^{10}$.

Since there is limited data available on the incidence and prevalence of liver diseases in Kashmir. This study aimed to find out whether there is an impact of dietary pattern on liver function parameters among the Kashmiri population who visited the main tertiary care hospital, Sher-I-Kashmir Institute of Medical Sciences, Soura Srinagar, for various ailments. This hospital is the valley's largest tertiary care hospital, providing the best healthcare management for patients from all over the valley.

\section{Materials and Methods}

This retrospective study included all subjects who visited SKIMS hospital from all districts of Kashmir valley for clinical advice after being diagnosed with a variety of ailments and were recommended to undergo various Biochemistry investigations by doctors of various specialties from the OPD/IPD. The analysis on different biochemical parameters was performed by the Department of Clinical Biochemistry, Sher-I-Kashmir Institute of Medical Sciences from March 2020 to November 2020. The patient's serum biochemical tests were performed on auto-analyzers (BECKMAN COULTER AU5800) using commercially available reagent kits from Beckman Coulter Ireland Inc. AST, ALT, LDH, and ALP were measured by the IFCC Reference method. Bilirubin and albumin were evaluated by DPD and Bromocresol Green method respectively.

Statistical data analysis was performed on version 16 of the STATA software (STATA Corp., College Station, TX, USA). The study was interpreted as Mean \pm Standard deviation.

\section{Results}

Clinicians from various specialties of the hospital recommended 18462 patients for different biochemical parameters like Kidney function and Liver function test parameters. Some were recommended whole LFT panel and some few parameters. Among all, the AST, ALT, TBIL, TP, Albumin, ALP, and LDH were documented. Except for ALP and LDH, all liver parameters were found within the acceptable range. However, ALP and LDH were recorded as $148.66 \pm 131.86$ and $260.25 \pm 50.25$ respectively. This data is summarized in Table 1 .

Table 1. Mean value of liver function parameters

\begin{tabular}{|c|c|c|c|c|c|}
\hline Parameter & Normal Range & Number & Mean ( \pm SD & Min & Max \\
\hline AST & $0-45$ & 7715 & $39.06 \pm 31.0$ & 02 & 392 \\
\hline ALT & $0-45$ & 12084 & $38.81 \pm 37.8$ & 01 & 458 \\
\hline TBIL & $0.3-1.5$ & 12573 & $0.91 \pm 0.45$ & 0.01 & 82.85 \\
\hline TP & $5.5-8.5$ & 12622 & $7.31 \pm 0.789$ & 0.03 & 13.2 \\
\hline Alb & $3.5-5.2$ & 13147 & $4.22 \pm 0.817$ & 0.19 & 8.7 \\
\hline ALP & $30-141$ & 12762 & $148.66 \pm 131.86$ & 32 & 1257 \\
\hline LDH & $25-248$ & 12181 & $260.25 \pm 50.25$ & 27 & 1325 \\
\hline
\end{tabular}


Asian Journal of Basic Science \& Research Volume 3, Issue 2, Pages 34-39, April-June 2021

Table 2. Percentage of Normal, Elevated and Low liver biochemical parameters

\begin{tabular}{|c|c|c|}
\hline Variable & $\mathbf{N}$ & Percentage \\
\hline \multicolumn{3}{|l|}{ AST } \\
\hline Normal & 6059 & 79 \\
\hline Elevated & 1656 & 21 \\
\hline \multicolumn{3}{|l|}{ ALT } \\
\hline Normal & 9219 & 76 \\
\hline Elevated & 2865 & 24 \\
\hline \multicolumn{3}{|c|}{ Total Bilirubin } \\
\hline Normal & 11040 & 88.09 \\
\hline Elevated & 1156 & 9.22 \\
\hline Low & 377 & 3 \\
\hline \multicolumn{3}{|c|}{ Total Protein } \\
\hline Normal & 12169 & 96.41 \\
\hline Elevated & 267 & 2.11 \\
\hline Low & 186 & 1.47 \\
\hline \multicolumn{3}{|l|}{ Albumin } \\
\hline Normal & 10808 & 82.20 \\
\hline Elevated & 513 & 3.90 \\
\hline Low & 1826 & 13.88 \\
\hline \multicolumn{3}{|l|}{ ALP } \\
\hline Normal & 8014 & 62.79 \\
\hline Elevated & 4748 & 37.2 \\
\hline \multicolumn{3}{|l|}{ LDH } \\
\hline Normal & 7187 & 59 \\
\hline Elevated & 4994 & 41 \\
\hline
\end{tabular}

On a superficial look, the percentage of normal, elevated, and low liver biochemical were illustrated in Table 2.

\section{Discussion}

The major findings of this study were that LDH and ALP were a little higher to some extent among the Kashmiri population. Although both enzymes (LDH and ALP) are the liver enzymes indicating liver damage ${ }^{11}$, apart from this they are the biomarkers of the diversity of diseases ${ }^{12,13}$. LDH is a well-known biomarker for myocardial Ischemia hence associated with the risk of coronary artery diseases ${ }^{14}$. The clinical studies have shown that LDH is elevated in the COVID-19 patients ${ }^{15}$. Mudassar et al., also reported elevation of LDH in patients with COVID-19 
among the Kashmiri population ${ }^{16}$.ALP is also associated with heart diseases as a diagnostic marker to assess stroke ${ }^{17,18,19}$.The increased serum ALP is directly associated with the risk of cardiovascular stroke.

It has been seen that the people of Kashmir are consuming a more fat-rich diet (wazwan) ${ }^{10}$, junk food that contains saturated fats and more sugar that might have effects on these biochemical parameters like ALP and LDH. Most clinicians recognize intake of fat-rich dietary habits with heart disease.

There is also a limitation in this study as it was an observational study with no follow-up with the participants.

\section{Conclusion}

Our data revealed that the biochemical parameters like AST, ALT, total bilirubin, total protein, albumin were normal but the ALP and LDH were increased to some very less extent. One of the reasons for the increased levels of these two parameters could be the diet intake of more saturated fats.

\section{Acknowledgement}

The authors are highly thankful to the technical staff of Department of Clinical Biochemistry (SKIMS) for their support in data sample analysis.

\section{Declarations}

\section{Source of Funding}

This research did not receive any specific grant from funding agencies in the public, commercial, or not-for-profit sectors.

\section{Competing Interests Statement}

The authors declare no competing financial, professional and personal interests.

\section{Ethical Approval}

Ethical approval for this research was given based on institutional guidelines.

\section{Consent to participate}

The consent to participate in this research was sought for and approved by the subjects to be used

\section{Consent for publication}

We declare that we consented for the publication of this research work.

\section{Availability of data and material}

Authors are willing to share data and material according to the relevant needs.

\section{References}

1. Mokdad AA, Lopez AD, Shahraz S, et al. Liver cirrhosis mortality in 187 countries between 1980 and 2010: a systematic analysis. BMC Med. 2014; 12:145. doi: 10.1186/s12916-014-0145-y. 
2. Benedict M, Zhang X. Non-alcoholic fatty liver disease: An expanded review. World J Hepatol. 2017; 9(16):715-732. doi:10.4254/wjh.v9.i16.715.

3. Moore JX, Chaudhary N, Akinyemiju T. Metabolic Syndrome Prevalence by Race/Ethnicity and Sex in the United States, National Health and Nutrition Examination Survey, 1988-2012. Prev Chronic Dis. 2017; 14: E24. doi:10.5888/pcd14.160287.

4. Liver Disease in India. World Life Expectancy. Accessed May 15, 2021. https://www.worldlifeexpectancy. com/india- liver-disease.

5. Duseja A, et al. Non-alcoholic Fatty Liver Disease and Metabolic Syndrome-Position Paper of the Indian National Association for the Study of the Liver, Endocrine Society of India, Indian College of Cardiology and Indian Society of Gastroenterology. J Clin Exp Hepatol. 2015; 5(1): 51-68. doi:10.1016/j.jceh. 2015.02.006.

6. Duseja A, et al. The clinicopathological profile of Indian patients with nonalcoholic fatty liver disease (NAFLD) is different from that in the West. Dig Dis Sci. 2007; 52(9): 2368-2374. doi:10.1007/s10620-006-9136-y

7. McAfee AJ, McSorley EM, Cuskelly GJ, et al. Red meat consumption: An overview of the risks and benefits. Meat Sci. 2010; 84(1): 1-13. doi:10.1016/j.meatsci.2009.08.029.

8. Red meat in the diet - Williamson - 2005 - Nutrition Bulletin - Wiley Online Library. Accessed May 17, 2021. https://online library. wiley.com/doi/full/10.1111/j.1467-3010.2005.00525.x.

9. Khuroo M. Liver Disease In Kashmir Challenges \& Hope. Gt Kshmir Engl Dly Srinagar. April 8, 2012.

10. Parray I, Zargar S, Khan B, et al. Ultrasonographic Prevalence of Non-Alcoholic Fatty Liver Disease (Nafld) in Kashmir Valley School Children. Int J Sci Res. 2012; 2: 299-301. doi:10.15373/22778179/mar2013/92.

11. Giannini EG, Testa R, Savarino V. Liver enzyme alteration: a guide for clinicians. CMAJ Can Med Assoc J. 2005; 172(3): 367-379. doi:10.1503/cmaj.1040752.

12. Mythili S, Malathi N. Diagnostic markers of acute myocardial infarction. Biomed Rep. 2015; 3(6): 743-748. doi:10.3892/br.2015.500.

13. Sharma U, Pal D, Prasad R. Alkaline Phosphatase: An Overview. Indian J Clin Biochem. 2014; 29(3): 269-278. doi: 10.1007/s12291-013-0408-y.

14. Schmiechen NJ, Han C, Milzman DP. ED use of rapid lactate to evaluate patients with acute chest pain. Ann Emerg Med. 1997; 30(5): 571-577. doi:10.1016/s0196-0644(97)70071-4.

15. Henry BM, Aggarwal G, Wong J, et al. Lactate dehydrogenase levels predict coronavirus disease 2019 (Covid-19) severity and mortality: A pooled analysis. Am J Emerg Med. 2020; 38(9): 1722-1726. doi:10.1016/j. ajem.2020.05.073.

16. Rasool R, Rashid G, Douhath S, Mir S, Mudassar S. Variation of biochemical markers in patients with Covid -19 in ethnic kashmiri population -an observational study. World J Pharm Pharm Sci. 2021; 10: 1538-1546. doi: 10.20959/wjpps20215-18976. 
17. Wannamethee Sasiwarang Goya, Sattar Naveed, Papcosta Olia, Lennon Lucy, Whincup Peter H. Alkaline Phosphatase, Serum Phosphate, and Incident Cardiovascular Disease and Total Mortality in Older Men. Arterioscler Thromb Vasc Biol. 2013; 33 (5): 1070-1076. doi:10.1161/atvbaha.112.300826.

18. Tonelli Marcello, Sacks Frank, Pfeffer Marc, Gao Zhiwei, Curhan Gary. Relation between Serum Phosphate Level and Cardiovascular Event Rate in People with Coronary Disease. Circulation. 2005; 112 (17): 2627-2633. doi:10.1161/circulationaha.105.553198.

19. Kunutsor SK, Apekey TA, Khan H. Liver enzymes and risk of cardiovascular disease in the general population: A meta-analysis of prospective cohort studies. Atherosclerosis. 2014; 236(1): 7-17. doi:10.1016/j.athe rosclerosis.2014.06.006. 